\title{
A Quantitative Analysis For The Tanzania Industries Performance And Productivity
}

\author{
Nuhu A. Sansa \\ Guangxi University, China.
}

\begin{tabular}{lll}
\multicolumn{3}{l}{ Article Information } \\
Received $\quad:$ & 28 April 2020 \\
Revised $\quad:$ & 26 May 2020 \\
Accepted $\quad: \quad$ 03 June 2020 \\
Published $\quad: \quad$ 10 June 2020
\end{tabular}

Abstract- Literature evidence manifests that the Tanzania manufacturing sector's contribution to the economic development is inadequate and the targeted performance and productivity of the sector were never realized. With that regard the fundamental question for Tanzania Industries performance and productivity becomes the centred debate and significant for the investigation. This study focuses on investigating the performance of the industries and the labour force productivity during the period from 1996 to 2015 in Tanzania. The study considers employing the Ordinary Least Square (OLS) method to analyze the average annual growth rates of the total Gross Domestic Product (GDP), employment and export during the period from 1996 to 2015. Time series macroeconomic data during the period from 1996 to 2015 for Tanzania were collected from the World Bank. To assess the performance of the Tanzania industries particularly the annual average marginal performance, the Gross Domestic Product (GDP) and the export's yearly average growth rate for the periodic 1996-2000, 2001-2005, 2006-2010, and 2011-2015 were evaluated. While investigating the labour force productivity the extra productivity of the employment labour force was evaluated during the period from 1996 to 2015 in Tanzania. The results of the investigatigation were in actual fact catching up the attention. The findings of the study reveals that the performance of the Tanzania industries is positive and meaningful while the labour force productivity is negative and insignificant during the period from 1996 to 2015 in Tanzania.

Nuhu A. Sansa

Email: nuhusansa09@gmail.com

Keywords: Tanzania Industries, Performance, and Productivity..

Copyright $\odot$ 2020: Nuhu A. Sansa. This is an open access distribution, and reproduction in any medium, provided Access article distributed under the Creative Commons Attribution License the original work is properly cited License, which permits unrestricted use.

Citation: Nuhu A. Sansa. "A Quantitative Analysis For The Tanzania Industries Performance And Productivity, "Journal of Science, Computing and Engineering Research, 1(2), 36-46, May-June 2020.

\section{INTRODUCTION}

Since the year of 1996 Tanzania has initiated significant efforts to transform the manufacturing sector and its productivity particularly to increase its contribution of the sector to the Gross Domestic Product (GDP) of the country. Among the key efforts initiated by the country through the ministry of trade and industry is launching and starting the implementation of the industrial policies to pilot the manufacturing sector ahead of achieving the industrialization and middle income status country by the year of 2025. Despite the significant efforts taken by the Tanzania Government focusing transforming the manufacturing sector to become the leading Gross Domestic Product (GDP) contributor and more productive for the economic growth of the country, the recent literature explores that the contribution of manufacturing sector to the country Gross Domestic Product (GDP) is still insufficient and the targeted results were never realized. The following evidence supports this statement.

Tanzania literature proves that the manufacturing sector of Tanzania's performance and productivity decline and the contribution of the sector to the country Gross Domestic Product (GDP) become smaller than expected. Regardless of the Government efforts including initiating and implementing industrial Policies and investments to the sector still the productivity of the sector and its industries were insignificant. Mbelle, (2005,.Pg.13) explored the situation stated that," First was the fact that the performance of the manufacturing sector was deteriorating, despite increased investments in the sector in the form of capacity expansion".

Regardless of the less contribution of the manufacturing sector to the country Gross Domestic Product (GDP), and insufficient implementation of the Tanzania industrial policies since were launched during the year of 1996, In Tanzania there is no academic work have been undertaken to investigate the productivity of Tanzania industries and its contribution to the Gross Domestic Product (GDP) of the country. This study is focusing on evaluating the Tanzania industries productivity during the period from 1996 to 2015 in Tanzania.

\section{MOTIVATION OF THE STUDY AND OBJECTIVE}

From the fact that the Tanzania literature explores that the contribution of the manufacturing sector and its industries to the economic development of the country is of 


\section{A Quantitative Analysis For The Tanzania Industries Performance And Productivity}

\section{Available at https://jscer.org}

very small amount and the desired economic development targets through the productivity of the manufacturing sector were never realized in Tanzania. This fact pushed the probe for the of Tanzania industries productivity during the period from 1996 to 2015 in Tanzania. The following grounds support this statement.

Tanzania literature proves that the manufacturing sector of Tanzania's performance and productivity decline and the contribution of the sector to the country Gross Domestic Product (GDP) become smaller than expected. Regardless of the Government efforts including initiating and implementing industrial Policies and investments to the sector still the productivity of the sector and its industries were insignificant. Mbelle, (2005,.Pg.13) explored the situation stated that," First was the fact that the performance of the manufacturing sector was deteriorating, despite increased investments in the sector in the form of capacity expansion".

The Tanzania Manufacturing sector and its industries for a very long period of time stand underperform and inactive in the development of the country. This circumstance pointed out by (Africa Development Bank Tanzania Country Report 2014., Pg.3) stated that "Tanzania's Manufacturing sector is relatively small and over the long run has failed to develop".

Despite the significant efforts taken by the Tanzania Government focusing transforming the manufacturing sector to become the leading Gross Domestic Product (GDP) contributor and more productive for the economic growth of the country, the recent literature explores that the contribution of manufacturing sector to the country Gross Domestic Product (GDP) is still insufficient and the targeted results were never realized. Regarding the insufficient contribution of the manufacturing sector to the economic development of Tanzania the present study is undertaken to evaluate the performance and the productivity of Tanzania industries during the period from 1996 to 2015 in Tanzania. In addition to that, the study will generate new knowledge which manifest the fact about the Tanzania industries's performance and productivity during the period from 1996 to 2015 in Tanzania. Concerning the usefulness of the study, The study will be useful to the economics discipline specifically industrial economics and Tanzania as a country at large.

\section{A. Objective Of The Study}

This study focuses on investigating the performance of the industries and the labour force productivity during the period from 1996 to 2015 in Tanzania.

\section{LITERATURE REVIEW}

Tanzania literature proves that the manufacturing sector of Tanzania's performance and productivity decline and the contribution of the sector to the country Gross Domestic
Product (GDP) become smaller than expected. Regardless of the Government efforts including initiating and implementing industrial Policies and investments to the sector still the productivity of the sector and its industries were insignificant. Mbelle, (2005,.Pg.13) explored the situation stated that," First was the fact that the performance of the manufacturing sector was deteriorating, despite increased investments in the sector in the form of capacity expansion".

The world evidence shows that the industry sector is the one contributing to the large percent of the different countries' economies and quickly transforming their economies to better and achieving industrialization. This is very different to the Tanzania manufacturing sector and its industries, where the sector is not in the larger contribution and success of the Tanzania economy. John (2016,.Pg.1) insisting and writing, "A sector that has been largely absent from the Tanzania success story is industry".

It has been evidendent that since the Tanzania government undertook the different reforms to stimulate its economic development to its people's different sectors including mining and tourism showed the positive and desired results however the manufacturing sector stayed stagnant and back as planned. Kahyarara , (2013,.Pg.86) describe the circumstance stating; "This is a puzzle because some sectors such as mining and tourism have shown impressive performance after taking advantage of reforms, whereas Tanzania manufacturing still lags behind".

The Tanzania Government made substantial efforts to transform the manufacturing sector of Tanzania including the initiating of the Tanzania industrial policies in the year of 1996 and encourage the private sector to control the productivity of the Tanzania industries and lead the sector towards industrialization process. The Tanzania Invest (2019,.Pg.1) explained that, "The Government of Tanzania introduced its Sustainable Industrial Development Policy (SIDP) in 1996 to phase itself out of investing directly in productive activities and let the private sector take that role".

Tanzania from the independence on the process to transform its economy and industrial developments one of the strategies was the initiation of the Arusha Declaration during the year 1967 to restructure the Tanzania economy and social parameters including equality, socialism and self reliance within the country. Darkoh , (1984,.Pg.47) insisting that; "Since the adoption of the Arusha Declaration in 1967, Tanzania has charted a course for its industrial development within the framework of the economic and social objectives of equality, socialism and self-reliance".

Literature explores the weight undertaken subject to strengthening the organisations and different firms abilities to raise productivity while the innovation factors left behind and stagnant within the manufacturing sector in Tanzania. This matter is well elaborated by (Goedhuys, Janz, and

Page 37 
Mohnen,. 2006.,Pg.,14) stating that; "The importance of the institutional set up in explaining productivity differences among manufacturing firms in a developing country like Tanzania, and the lack of importance attached to direction innovation factors".

Evidence shows that different countries count the manufacturing sector as an most important sector towards the process of transforming the economy to the rapidly economic development and industrialization. Likewise, Tanzania literature insists on the significance of the manufacturing sector towards building the economy of the country and economic development in general (Wangwe, Mmari, Aikael, Rutatina, Mboghoina and Kinyondo,.. 2016.,Pg. 9) clarifies that; "Importance of the manufacturing sector to the national economy has varied across different periods since independence, however, in recent years its contribution to the national income and hence its importance has been on the rise".

The Tanzania Manufacturing sector and its industries for a very long period of time stand underperform and inactive in the development of the country. This circumstance pointed out by (Africa Development Bank Tanzania Country Report 2014., Pg.3) stated that "Tanzania's Manufacturing sector is relatively small and over the long run has failed to develop".

The Tanzania manufacturing sector has come across different obstacles since the independence of Tanzania. Some of these challenges are the high oil prices and interest rates from outsiders forces. Due to the challenges the development of the sector has become unachievable, Mbelle., (2000,.Pg.16) explained that; "Tanzania's manufacturing sector has long suffered serious constraints. In the 1970s and 1980s they predominantly consisted of external shocks such as high oil prices and interest rates". The estimation economic growth of Tanzania by the year of 2020 counts much contribution by the industry and manufacturing sector. This justified by the Africa Development Group Report (2020., Pg.,1) written; “A markedly diversified economy, characterized by robust private consumption, substantial public spending, strong investment growth, and an upturn in exports underpinned the positive outlook. Tourism, mining, services, construction, agriculture, and manufacturing are notable sectors".

The role of the policies and its importance to the transformation of the Tanzania manufacturing sector to better has become the most centered instrument to achieve the desired economic development in Tanzania. Recently Tanzania undertaking the industrialization process and the policy agenda well elaborated by Wangwe and Msami (2016.,Pg.1) clarifying that; "The current development agenda, however, has brought industrial development back to be one of the policy priorities".
To practice the industrialization successfully the literatures suggested that the agriculture sector must be well prepared in terms of productivity to support the industrial sector. The meaning is the agriculture sector must be very ready to produce enough production which basically needed the the manufacturing sector in Tanzania. Szirmai and Lapperre (1999.,Pg.6) insist that; "One of the important prerequisites cited by Lapperre is that industrialization requires prior increases in agricultural productivity".

Tanzania experiences the highly mobility of the labour force in the industrial sector market which leads to the slow down of the industries productivity in Tanzania. The world bank Group (2018.,Pg.5) explaining this fact in detail, stated that "Raising productivity, however, remains difficult because the labor shifts to manufacturing and services have mainly taken place in the informal sector".

Some of the Tanzania literature manifests how the Tanzania country counted among the last countries involved in the process of industrialization. Szirmai, Prins and Schulte (2002) describe that concept of Tanzania as from the last point to initiate the industrialization journey stating that; "Tanzania is a late late-comer to the process of industrialisation".

The Sustainable Industrial Development Policy (SIDP) 1996 was adopted with the objective of implementing the government's decision of withdrawing the public sector from engagement in production activities and enabling the private sector to become the principal vehicle for economic growth.(Tanzania Ministry Of Industry and Trade,. 2011.,Pg.1).

\section{RESEARCH METHODOLOGY}

To evaluate the performance and productivity of Tanzania industries in Tanzania the contemporary academic work employed the Time series data from the World Bank during the period from 1996 to 2015 for the Tanzania Gross Domestic Product (GDP), Manufacturing sector (GDP), Tanzania Employment, Manufacturing sector Employment, Tanzania Export and Manufacturing sector Export.

The study evaluated the yearly growing percent rates of Gross Domestic Product (GDP), Employment and Exports of Tanzania Industries during the period from 1996 to 2015. The growing rate evaluated by the following regression semi-log model:

In $\mathrm{EQ} \mathrm{i}=\mathrm{X} 0+\mathrm{X} 1 \mathrm{t}+\mathrm{Xi}$

From the above equation : A0 and A1 stand as coefficients, $\mathrm{Xi}$ stands as random disturbance, and EQi stand as dependent variable factor in the natural log, while $\mathrm{t}$ stand for Time period from the year 1996 to 2015.

The growing amount and figure (Rate) evaluated by the following equation

$\mathrm{Rxy}=\mathrm{X} 1 * 100$.

The present study to compute the yearly growing figure for the divided periods of 1996 - 2000, 2001 - 2005, 2006-

Page 38 
2010, and 2011-2015, the slope dummy and the intercept dummy have been applied (Gujarati, 2003). The study particularly employed the regression equation:

$\mathrm{In} \mathrm{EQi}=\mathrm{Xo}+\mathrm{X} 1 \mathrm{t}+\mathrm{X} 2 \mathrm{D} 1+\mathrm{X} 3(\mathrm{D} 1 * \mathrm{t})+\mathrm{X} 4 \mathrm{D} 2+$ $\mathrm{X} 5(\mathrm{D} 2 * \mathrm{t})+\mathrm{X} 6 \mathrm{D} 3+\mathrm{X} 7(\mathrm{D} 3 * \mathrm{t})+\mathrm{Xi}$

From the above equation:

$$
\begin{aligned}
\text { D1 }(\text { First Dummy) }= & 1996 \text { to } 2000=0 \\
& 2001 \text { to } 2015=1 \\
\text { D2 }(\text { Second Dummy) }= & 2001 \text { to } 2005=0 \\
& 2006 \text { to } 2015=1 \\
\text { D3 }(\text { Third Dummy) }= & 2006 \text { to } 2010=0 \\
& 2011 \text { to } 2015=1
\end{aligned}
$$

From the equation, $\mathrm{X} 0, \mathrm{X} 1, .$. Stand as Coefficients, $\mathrm{Xi}$ stand as the random disturbance, while EQi and t stand as referred from the equation number 1 .

Referring the regression equation, growing amount figure for the four divided periods were estimated by the following equation:

Rxy1996-2000 $=(X 1) * 100$

Rxy2001-2005 $=(X 1+X 3) * 100$

$\mathrm{Rxy} 2006-2010=(\mathrm{X} 1+\mathrm{X} 3+\mathrm{X} 5) * 100$.

$\mathrm{Rxy} 2011-2015=(\mathrm{X} 1+\mathrm{X} 3+\mathrm{X} 5+\mathrm{X} 7) * 100$

Key policy stakeholders and investigators believe and assume that all economic variables employed in this study were subject to increase as the time goes, the economic variables applied by the present study including Tanzania Gross Domestic Product (GDP), manufacturing sector GDP, Tanzania Employment, Manufacturing sector employment, Tanzania Export and Manufacturing sector export.

In addition to that, the present study assumes yearly growing amount in the given factors during the period 2011 to 2015 is greater than that of during the period 2006 to 2010. While assumes yearly growing amount in the given factors during the period 2006 to 2010 is greater than that of during the period 2001 to 2005 . In addition to that, the study assumes yearly growing amount in the given factors during the period 2001 to 2005 is greater than that of during the period 1996 to 2000. This assumption could be equated as follows:

Rxy 2011 to $2015>\mathrm{R}$ xy 2006 to 2010

Rxy 2006 to $2010>\mathrm{R}$ xy 2001 to 2005

Rxy 2001 to 2005 > R xy 1996 to 2000

From the above equations, the meaning is:

$(\mathrm{X} 1+\mathrm{X} 3+\mathrm{X} 5+\mathrm{X} 7) * 100>(\mathrm{X} 1+\mathrm{X} 3+\mathrm{X} 5) * 100$

$(\mathrm{X} 1+\mathrm{X} 3+\mathrm{X} 5) * 100>(\mathrm{X} 1+\mathrm{X} 3) * 100$

$(\mathrm{X} 1+\mathrm{X} 3) * 100>\mathrm{X} 1 * 100$

Evaluating the Employment labour marginal productivity this academic work employed the Cobb - Douglas production function (Cobb and Douglas, 1928) and constant Elasticity of Substitution (CES) production function (Arrow et al., 1961), same applied by Sadhu and Mahajan (1982) and Gaur and Padney (2003), and Greene (2005) respectively, which are classified and stated as below:

$\mathrm{Oi}=\mathrm{EL} 1 \mathrm{Ui}$.
From the above equation, Oi is the output, EL represents Employment labour, and 1 is the quantity of labour applied in the production mechanism, and Ui stands for random disturbance factor.

Extra productivity of Employment labour evaluated in the Double Log model below:

InOi=InA+XIn L

From the above equation: $\mathrm{X}$ represents Elasticity of Employment Labour during the time production took place.

\section{A. Performance of the Tanzania Industries}

To investigate the performance of Tanzania industries during the period from 1996 to 2015 in Tanzania, the contemporary study employs the two macroeconomic variables that are Gross Domestic Product (GDP) and the Export particularly Tanzania Gross Domestic Product (GDP), Manufacturing Gross Domestic Product, Tanzania Exports and Manufacturing sector Export. Given the macroeconomic data from the World Bank during the period from 1996 to 2015 the study computes the average performance annually, for the dived period (1996-2000, 2001-2005, 2006-2010, and 2011-2015), and for the whole period from the year 1996 to 2015 to evaluate the performance of the Tanzania industries for the given period.

\section{B. Gross Domestic Product (GDP)}

Regarding the Gross Domestic Product (GDP), the present study explores the performance of Tanzania industries through manifesting the increase of the Tanzania Gross Domestic Product (GDP) from $4.544 \%$ in the year of 1996 to $6.161 \%$ in the year of 2015. Similarly the manufacturing sector GDP percentage contribution to the total Tanzania GDP increased from $13.03 \%$ in the year of 1996 to $24.49 \%$ in the year of 2015. Gross Domestic Product (GDP) annual average amount computation manifests that; Tanzania Gross Domestic Product (GDP) annual average rate recorded $5.03 \%$, and recording the decrease of the rate from $27.28 \%$ in the year of 1996 to $8.48 \%$ in the year of 2015 , while the divided four periods annual average rate manifests the record of $6.83 \%$ (19962000), $11.45 \%$ (2001-2005), -2.41 (2006-2010) and $4.24 \%$ (2011-2015).

Apart from that, the manufacturing sector GDP annual average recorded $4.08 \%$, and recording the improvement and increase of the sector annual average GDP from $-2.95 \%$ in the year of 1996 to $-2.61 \%$ in the year of 2015 , while the divided four periods from the year 1996 to 2015 the manufacturing sector annual GDP recorded 9.38\% (19962000), $3.73 \%$ (2001-2005), 0.69\% (2006-2010) and $2.53 \%$ (2011-2015).

Referring appendix number 2 the study shows extra (marginal) annually average productivity of both Tanzania Gross Domestic Product and the Manufacturing sector GDP declined respectively from the interval period (19962005)and (2006-2015). From the first ten years interval 
(1996-2005) Tanzania Gross Domestic Product recorded $9.142 \%$ while Manufacturing sector recorded $1.61 \%$, The percentage decline to the second ten years interval (20062015) were recorded $0.915 \%$ for Tanzania Gross Domestic Product and $1.61 \%$ for Manufacturing sector GDP. That means regarding the Gross Domestic Product the Tanzania industries marginal productivity were declining and deteriorating during the period from the year 1996 to 2015 in Tanzania.

Appendix 1 : From the World Bank given data, the following table shows the Tanzania Gross Domestic Product (GDP) and the Manufacturing sector GDP during the period from 1996 to 2015 in Tanzania. Where, Y represents the Year, T-GDP represents Tanzania Gross Domestic Product (GDP) and MI-GDP represents the manufacturing sector GDP.

\begin{tabular}{|c|c|c|c|c|c|c|}
\hline $\mathbf{Y}$ & T-GDP & AV1 & AV2 & $\begin{array}{l}\text { MI- } \\
\text { GDP }\end{array}$ & AV1 & AV2 \\
\hline \multicolumn{7}{|l|}{1995} \\
\hline 1996 & 27.28 & & & -2.95 & & \\
\hline 1997 & -22.43 & & & -0.21 & & \\
\hline 1998 & 5.22 & $\begin{array}{l}6.83 \\
2\end{array}$ & & 54.41 & 9.376 & \\
\hline 1999 & 31.14 & & & -1.43 & & \\
\hline 2000 & -7.05 & & & -2.94 & & \\
\hline & & & $\begin{array}{l}9.14 \\
2\end{array}$ & & & 6.553 \\
\hline 2001 & 34.28 & & & 0.88 & & \\
\hline 2002 & 16.83 & & & 10.91 & & \\
\hline 2003 & -5.92 & $\begin{array}{l}11.4 \\
54\end{array}$ & & 8.14 & 3.73 & \\
\hline 2004 & 12.45 & & & -0.6 & & \\
\hline 2005 & -0.37 & & & -0.68 & & \\
\hline 2006 & -12.63 & & & -0.41 & & \\
\hline 2007 & 3.63 & - & & 1.54 & & \\
\hline 2008 & -16 & 2 & & 2.33 & 0.69 & \\
\hline 2009 & -7.33 & & & -8.68 & & \\
\hline 2010 & 20.27 & & $\begin{array}{l}0.91 \\
5\end{array}$ & 8.67 & & \\
\hline 2011 & 21.07 & & & 20 & & 1.61 \\
\hline 2012 & -41.35 & 4.24 & & -3.73 & & \\
\hline 2013 & 50.71 & 2 & & 0.19 & 2.53 & \\
\hline 2014 & -0.74 & & & -1.2 & & \\
\hline 2015 & -8.48 & & & -2.61 & & \\
\hline
\end{tabular}

\section{The Correlation Between Tanzania Gross Domestic Product (GDP) And The Manufacturing Sector Gross Domestic Product (GDP)}

The present study to find the correlation between the Tanzania Gross Product (GDP) and the manufacturing sector Gross Domestic Product (GDP) assumes the Tanzania Gross Domestic Product (GDP) stand as dependent variable while manufacturing sector Gross Domestic Product stand as independent variable.

The findings of the study reveals the positive and meaningful relationship between Tanzania Gross Domestic Product (GDP) and manufacturing sector Gross Domestic Product. The regression outcome manifests the coefficient of 0.2297 which means for every additional increase in manufacturing sector Gross Domestic Product similarly the Tanzania Gross Domestic Product (GDP) increased by 0.2297 points (Table number 1 below). 
Table 1: Regression Results Between Tanzania Gross Domestic Product (GDP) and Manufacturing sector Gross Domestic Product (GDP) during the period from 1996 to 2015.

\begin{tabular}{|c|c|c|c|c|}
\hline $\mathbf{V}$ & CT & SD & $\mathbf{T}$ & $\mathbf{P}$ \\
\hline SR & 0.2297 & 0.09697 & 2.3687 & 0 \\
\hline $\mathrm{C}$ & 0.9 & & & 0 \\
\hline $\mathrm{R} 2$ & 0.4365 & & & \\
\hline AR & 0.4052 & & & \\
\hline SER & 1.5478 & & & \\
\hline
\end{tabular}

$\mathrm{NOB}=20$

Origin: Regression results from Appendix number 1

Where: V is Variable, CT is Coefficient, C is Constant, SD is the Standard Deviation, T is T-Statistic , P is Probability, SR is Slope of the regression line, $\mathrm{R} 2$ is R-Squared, AR is Adjusted R-Square, SER is Standard Error of Estimation NOB is number of Observation.

\section{D.Hypothesis Test for the Correlation between Tanzania Gross Domestic Product and Manufacturing Sector (Industry) Gross Domestic Product}

From the regression calculations the study assumes Tanzania Gross Domestic Product (GDP) to be a dependent variable while Manufacturing sector (Industry) Gross Domestic Product (GDP) to be an independent variable. Regarding regression calculation results, The study finds the least squares regression line is

$\mathrm{Y}=0.9+0.2297 \mathrm{X}$

The study finds the standard deviation is 0.09697 .

From the above equation, $\mathrm{b}$ is 0.9 , and because it is positive means greater than zero not to accept null hypothesis instead accept alternative hypothesis.

Null and Alternative Hypothesis :

Ho : $\mathrm{B}=0$

$\mathrm{H} 1: \mathrm{B}>0$

Thus, The Test Statistic t0.01;(20-2) $=2.552$

Rejection Part of Ho is $t$ values of 2.552 or greater than . Given $\mathrm{t}<2.552$, null hypothesis may not be declined. From the Regression results $\mathrm{t}=\mathrm{b} / \mathrm{sb}=2.3687$

$=2.3687>2.552$

The meaning is there significant evidence the relationship between Tanzania Gross Domestic Product (GDP) and the Manufacturing Gross domestic Product (GDP) is strongly positive.

\section{a. Export}

The present study employed the macroeconomic indicator export to assess the performance of Tanzania industries during the period from 1996 to 2015 in Tanzania. From the World bank collected data the Tanzania export shows to decline where it recorded the amount of $19.937 \%$ in the year of 1996 as it decreased to $17.105 \%$ in the year of 2015. The situation is contrary to the manufacturing sector export where the data shows the increase of export done by the sector from $0 \%$ in the year of 1996 to $0.853 \%$ in the year of 2015. Regarding the annual export average, Tanzania export recorded the annual export average of $-0.665 \%$ which means the marginal performance for export was declined by the amount of $0.665 \%$ during the period from 1996 to 2015 in Tanzania. While the manufacturing sector annual average export recorded the amount of $2.332 \%$ which means the manufacturing sector average annual performance increased by the amount of $2.332 \%$ during the period from 1996 to 2015 in Tanzania. Apart from that the four divided sub periods the Tanzania export recorded the annual average performance productivity amounted to $-13.258 \%$ (19962000), 9.812\% (2001-2005), 3.102\% (2006-2010) and $2.316 \%$ (2011-2015). While the manufacturing sector exports annual average performance productivity for the four divided sub periods recorded the amount of $0 \%(1996-$ 2000), 0\% (2001-2005), 13.472\% (2006-2010) and -4.144\% (2011-2015).

The study investigation outcome indicates that the performance of Tanzania industries through the assessment if its exports increased and improved during the period from 1996 to 2015 in Tanzania. From the appendix number 4 the study shows the marginal annual export performance for the sub divided ten periods (1996-2005) and (20062015) were increased, where the Tanzania export marginal annual performance export were $-7.723 \%$ in the first ten years interval of (1996 - 2005) while the amount increased in the second ten years interval (2006 - 2015) to become $0.393 \%$. While the Tanzania industries manufacturing sector annual average marginal performance also increased from $0 \%$ during the first ten years interval (1996 - 2005) to become $4.664 \%$ in the second period of the ten years interval (2006 -2015) in Tanzania.

Appendix 3: From the Word Bank data indicators, the following are data for the Tanzania Export and manufacturing sector export during the period from 1996 to 2015 in Tanzania. Where $\mathrm{Y}$ stands for the year, T-EXP stands for the Tanzania Export and MI-EXP stands for the manufacturing sector export.

\begin{tabular}{lll}
$\mathbf{Y}$ & T-EXP & MI-EXP \\
\hline 1995 & 24.075 & 0 \\
1996 & 19.937 & 0
\end{tabular}




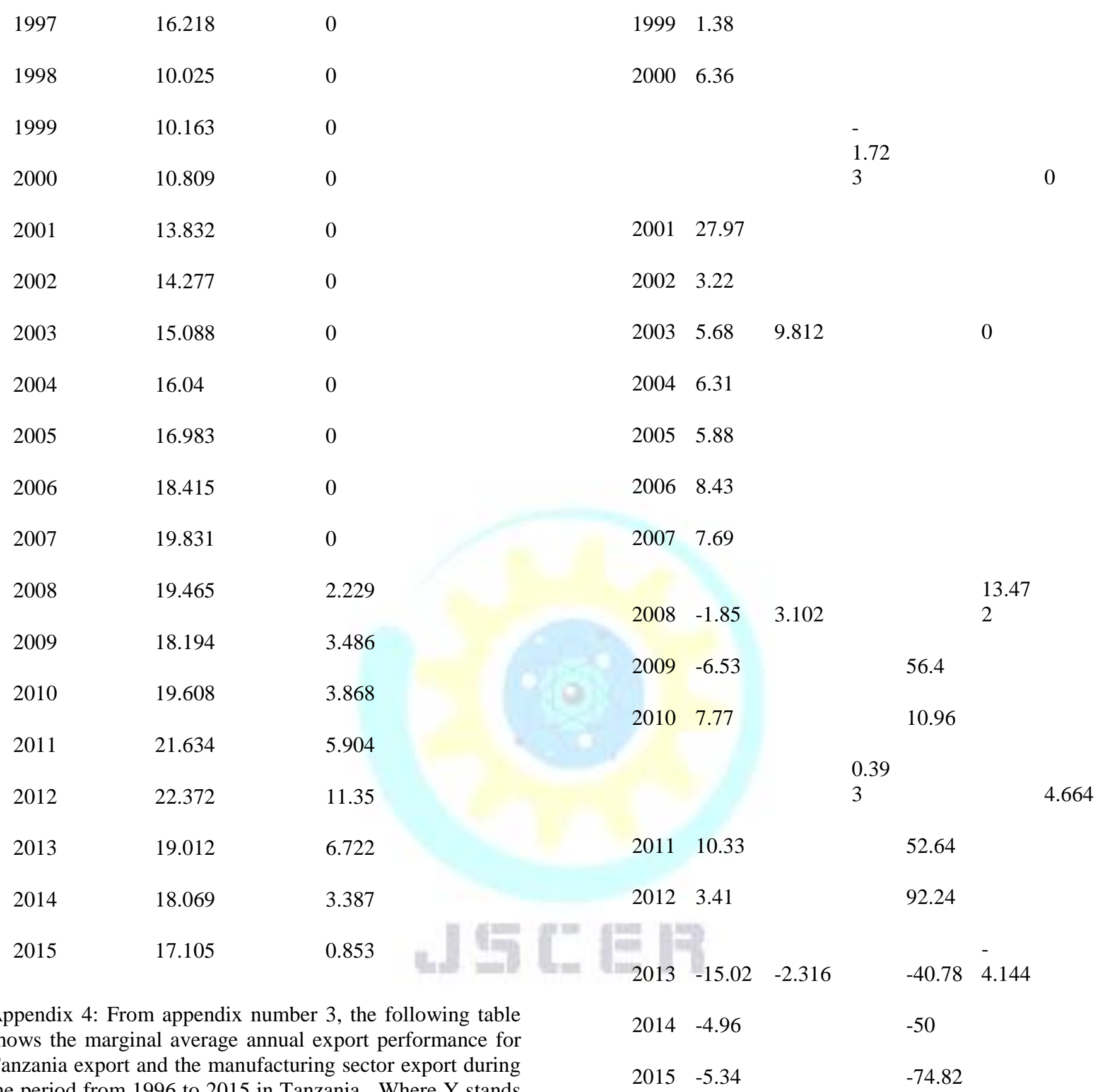
the period from 1996 to 2015 in Tanzania. Where $\mathrm{Y}$ stands for the year, T-EXP stands for the Tanzania export and MIEXP stands for the manufacturing sector export.

MI-

\section{Y T-EXP AV1 AV2 EXP AV1 AV2}

$\begin{array}{lll}1995 & & \\ 1996 & -17.19 & \\ 1997 & -18.65 & \\ 1998 & -38.19 & -13.258\end{array}$

E. The Correlation between Tanzania Export and the Manufacturing Sector Export

The present study to find the correlation between the Tanzania Export and the manufacturing sector Export assumes the Tanzania Export to be a dependent variable while manufacturing sector Export to be an independent variable.

The findings of the study reveals the positive and meaningful relationship between Tanzania Export and manufacturing sector Export. The regression outcome shows the coefficient of 0.7197 which means for every additional increase in manufacturing sector export similarly the 
Tanzania export increased by 0.7197 points (Table number 1 below).

Table 1: Regression Results Between Tanzania Export and Manufacturing sector Export during the period from 1996 to 2015.

\begin{tabular}{lllll}
$\mathbf{V}$ & CT & SD & T & P \\
\hline SR & 0.7197 & 0.2150 & 3.3475 & 0 \\
C & 15.49 & & 0 \\
R2 & 0.3816 & & \\
AR & 0.3472 & & \\
SER & 2.8982 &
\end{tabular}

NOB $=20$

Origin: Regression results from Appendix number 3

Where: V is Variable, CT is Coefficient,C is Constant, SD is the Standard Deviation, T is T-Statistic , P is Probability, SR is Slope of the regression line, R2 is R-Squared, AR is Adjusted R-Square, SER is Standard Error of Estimation NOB is number of Observation.

\section{F. Hypothesis Test for the Correlation between Tanzania Export and Manufacturing Sector (Industry) Export}

From the regression calculations the study assumes Tanzania Export to be dependent variable while Manufacturing sector (Industry) Export to be independent variable. Regarding regression calculation results, The study finds the least squares regression line is

$\mathrm{Y}=15.49+0.7197 \mathrm{X}$

The study finds the standard deviation is 0.2150

From the above equation, $\mathrm{b}$ is 0.7197 , and because it is positive means greater than zero not to accept null hypothesis instead accept alternative hypothesis.

Null and Alternative Hypothesis :

Ho : $\mathrm{B}=0$

$\mathrm{H} 1: \mathrm{B}>0$

Thus, The Test Statistic t0.01; (20-2) $=2.552$

Rejection Part of Ho is $t$ values of 2.552 or greater than . Given $\mathrm{t}<2.552$, null hypothesis may not be declined. From the Regression results $\mathrm{t}=\mathrm{b} / \mathrm{sb}=3.3475$

$=3.3475>2.552$

The meaning is there significant evidence the relationship between Tanzania Export and the Manufacturing Export is strongly positive.

\section{G. Productivity of the Tanzania Industries Employment}

The study applied the employment labour force and finds the annual average productivity of employed labour force within the Tanzania industries to assess the marginal productivity of industries during the period from 1996 to 2015 in Tanzania. The World Bank data given data manifests the Tanzania employment declined from $84.023 \%$ in the year of 1996 to $81.627 \%$ in the year of 2015 . While the situation is different to the manufacturing sector where the employment increased from 5.474\% in the year of 1996 to $12.79 \%$ in the year of 2015 . Concerning the annual average employment labour force, Tanzania annual average employment recorded $-0.084 \%$ which means there were decrease of the marginal employment labour force annually by the amount of $0.084 \%$ for Tanzania. While the manufacturing sector annual average employment labour force recorded the amount of $4.5375 \%$ which means the manufacturing sector marginal annual employment labour force were increased by the amount of $4.5375 \%$ during the period from 1996 to 2015 in Tanzania. Regarding the four sub divided periods the annual average marginal productivity Tanzania recorded $0.286 \%$ (1996-2000), $0.212 \%(2001-2005),-0.332 \%(2006-2010)$ and $-0.502 \%$ (2011-2015). While manufacturing sector the annual average marginal productivity for the four sub divided periods recorded $1.39 \%$ (1996-2000), 11.242\% (20012005), $2.932 \%$ (2006-2010) and 2.586\% (2011-2015).

The study findings discovered the deterioration of the marginal employment labour force for both Tanzania employment and Tanzania industries in the manufacturing sector during the period from 1996 to 2015 in Tanzania. Reference from the study appendix number six particularly for the two separated interval time from the first ten years interval (1996-2005) to the second ten years interval (20062015). For the first ten years interval Tanzania employment recorded $0.249 \%$ (1996-2005) where the figure declined to the second ten years interval to $-0.417 \%$ (2006-2015). Similarly to the manufacturing sector where the marginal employment labour force also declined from the amount of $6.316 \%$ during the first ten years interval (1996-2005) to $2.759 \%$ during the second ten years interval (2006-2015) in Tanzania.

Appendix 5: From the world Bank Data indicators, The following are the Tanzania employment and manufacturing sector employment data during the period from 1996 to 2015 in Tanzania. Where $\mathrm{Y}$ is the year, T-EMP is the Tanzania employment and MI-EMP is the manufacturing sector employment.

\begin{tabular}{lll}
$\mathbf{Y}$ & T-EMP & MI-EM \\
\hline 1995 & 84.022 & 5.396 \\
1996 & 84.023 & 5.474 \\
1997 & 84.071 & 5.529
\end{tabular}




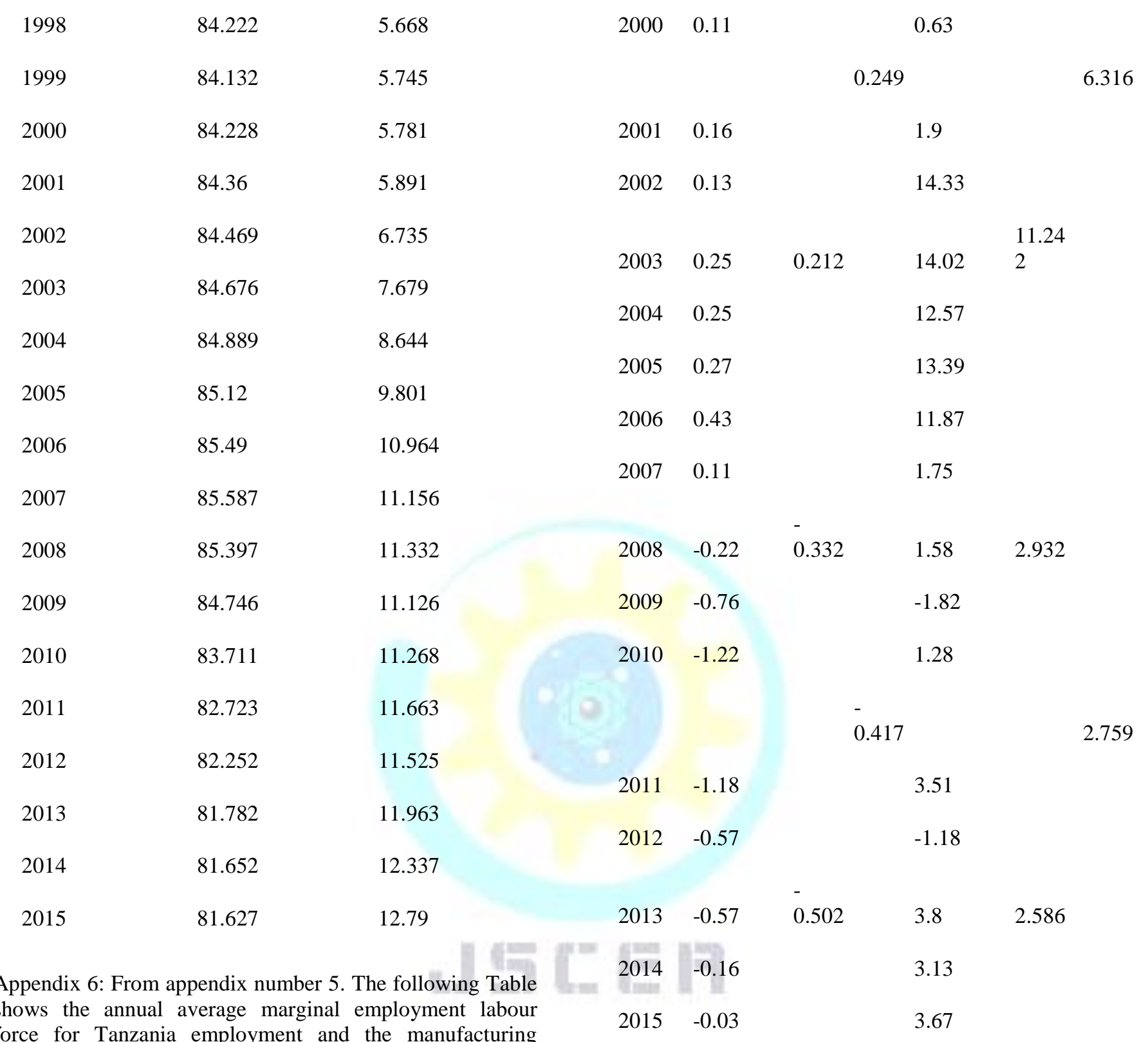
sector employment during the period from 1996 to 2015 in Tanzania. Where $\mathrm{Y}$ is the year, T-EMPL is the Tanzania employment and MI-EMP is the Manufacturing sector employment.

\section{Y T-EMPL AV1 AV2 MI-EMP AV1 AV2}

1995

$\begin{array}{lllll}1996 & 1.19 & & 1.45 & \\ 1997 & 0.06 & & 1 & \\ 1998 & 0.18 & 0.286 & 2.51 & 1.39 \\ 1999 & -0.11 & & 1.36 & \end{array}$

\section{H. The Correlation between Tanzania Employment and the Manufacturing Sector Employment}

The present study to find the correlation between the Tanzania Employment and the manufacturing sector Employment assumes the Tanzania Employment stands as a dependent variable while manufacturing sector Employment stands as an independent variable. The findings of the study reveals the negative and insignificant relationship between Tanzania Employment and manufacturing sector Employment. (Table number 1 below).

Table 1: Regression Results Between Tanzania Employment and Manufacturing sector Employment during the period from 1996 to 2015. 


\begin{tabular}{lllll} 
V & CT & SD & T & P \\
\hline SR & -0.1736 & 0.1130 & -1.5358 & 0 \\
C & 85.55 & & 0 \\
R2 & 0.1355 & & \\
AR & 0.0875 & & \\
SER & 1.3599 & & \\
NOB $=20$ & & &
\end{tabular}

Origin: Regression results from Appendix number 5

Where: V is Variable, CT is Coefficient,C is Constant, SD is the Standard Deviation, T is T-Statistic , P is Probability, SR is Slope of the regression line , R2 is R-Squared, AR is Adjusted R-Square , SER is Standard Error of Estimation NOB is number of Observation.

\section{Hypothesis Test for the Correlation between Tanzania Employment and Manufacturing Sector (Industry) Employment}

From the regression calculations the study assumes Tanzania employment to be dependent variable while Manufacturing sector (Industry) Employment to be independent variable. With reference to the regression results, the study outcome regression line is:

$\mathrm{Y}=85.55-0.1736 \mathrm{X}$

While, the study standard deviation is 0.1130

Regarding the above equation, $\mathrm{b}$ is -0.1736 , and because it is negative means less than zero accept null hypothesis while not accepting alternative hypothesis.

Null and Alternative Hypothesis:

Ho : $\mathrm{B}=0$

$\mathrm{H} 1: \mathrm{B}<0$

Thus, The Test Statistic t0.01 (20-2) $=2.552$

Rejection Part of Ho is t values of 2.552 or less than.

From the regression results

$\mathrm{t}=\mathrm{b} / \mathrm{sb}=-1.5358$

$=-1.5358<2.552$

The meaning is there significant evidence the relationship between Tanzania Employment and the Manufacturing Employment is strongly Negative.

\section{SUMMARY OF THE FINDINGS AND LIMITATIONS}

The results of the investigatigation were in actual fact catching up the attention. The findings of the study reveals that the performance of the Tanzania industries is positive and meaningful while the labour force productivity is negative and insignificant during the period from 1996 to 2015 in Tanzania.

\section{A. Limitation of the Study}

Due to the absence of the present time data the study did not manifest the performance and productivity of the Tanzania industries during the period from 2016 to 2020. This is the opportunity for future and further studies to investigate the performance and productivity of the Tanzania industries from the year of 2016 onwards.

\section{CONCLUSION AND RECOMMENDATION}

The present study was undertaken to investigate the performance and productivity of the Tanzania industries during the period from 1996 to 2015 in Tanzania. The findings of the study reveals that the performance of the Tanzania industries is positive and meaningful while the labour force productivity is negative and insignificant during the period from 1996 to 2015 in Tanzania.

\section{Recommendation}

Due to the fact that labour force productivity for the Tanzania industries is negative and meaningless during the period from 1996 to 2015 in Tanzania the Tanzania Government must review industrial policies and industrial employment policies guide to picture out the truly obstacles for the deterioration of the productivity labour force and suggesting the proper measures to overcome those challenges. The Tanzania Government should also consider to handle and eliminate the problem of high labour mobility in the manufacturing sector for the sustainable productivity and growth of the Tanzania industries.

Further study on this area must be done particularly to investigate the performance and productivity of the Tanzania industries through the other macroeconomic variables such as the initial production of industries, revenue, investment and capital from the time industrial policies were launched and started to be implemented in the year of 1996 .

For the sustainable industries performance and productivity the Tanzania Government should make great support to the private sector to pilot the manufacturing sector through providing the favorable environment for the investment including creating the new industrial bank with the low interest and very long term loans specifically to the manufacturing sector.

The Tanzania Government should as well invest more in research, innovation and new technology as the top priority to enhance the performance and productivity of the Tanzania industries.

\section{Acknowledgment}

I sincerely acknowledge the support of my country Tanzania the Guangxi University on the process making this study happen.

\section{REFERENCES}

[1] Aisha Al-Sadi1, Hana' Al-Theiabat.,"Smartphone-Assisted Location Identification Algorithm for Search and Rescue 
Services",8th International Conference on Information and Communication Systems (ICICS), 2017.

[2] Yu-Jia Chen, Student Member, IEEE Chia-Yu Lin, Student Member, IEEE and Li-Chun Wang.,"Sensors-Assisted Rescue Service Architecture in Mobile Cloud Computing", IEEE Wireless Communications and Networking Conference,2014.

[3] Noriyuki Suzuki, Jane Louie Fresco Zamora, Shigeru Kashihara, Suguru., Yamaguchi "Location Estimation of Immobilized Persons through SOS Message Propagation”, 2012.

[4] Xian Wu, Maciej Mazurowski, Zhen Chen, Nirvana Meratnia., Spare Message Dissemination System for Smart phones During Natural Disasters", 11th International Conference on ITS TeleCommunications, 2011.

[5] Yao-Nan Lien, Hung-Chin Jang, and Tzu-Chieh Tsai.,A MANET Based Spare Communication and Information System for Catastrophic Natural Disasters", ,2013.

[6] J. A. Besada, A. M. Bernardos, P. Tarrio, and J. R. Casar, "Analysis of tracking methods for wireless indoor localization," in Wireless Pervasive Computing, 2007. ISWPC '07.2nd International Symposium on, 2007.

[7] Kitasuka, T., K. Hisazumi, T. Nakanishi and A. Fukuda, "Positioning Techniques of Wireless LAN Terminals Using RSSI between Terminals", in Proceedings of the 2005 International Conference on Pervasive Systems and Computing (PSC-05), Las Vegas, Nevada, USA, 47-53,2005.

[8] W.C.Jakes, Microwave Mobile Communications, Wiley_Interscience, 1974.

[9] T. S. Rappaport, Wireless Communications Principles and Practice, New York: IEEE Press \& Prentice Hall PTR, 1996.

[10] "Castalia Wireless Sensor Netowrk Simulator - Home." [Online].Available:ttps://castalia.forge.nicta.com.au/index.php/en/. 2016.

[11] "OMNeT++ Discrete Event Simulator - Home." [Online]. Available: https://omnetpp.org/. 15-Dec-2016.

[12] C. Pu, "Evacuation Assisting Strategies in Vehicular Ad Hoc Networks," in IEEE Proc. UEMCON, November 2018.

[13] Ecuador Earthquake: Death Toll Jumps to 272; More Than2,500Injured,ttps://www.cnn.com/2016/04/17/americas/ecuad or-deadlyearthquake, Apr 18, 2016.

[14] H. Nishiyama, M. Ito, and N. Kato, "Relay-by-Smartphone: Realizing Multihop Device-to-Device Communications," IEEE Commun. Mag., vol. 52, no. 4, pp. 56-65, 2014.

[15] L. Bengtsson, X. Lu, A. Thorson, R. Garfield, and J. V. Schreeb, "Improved Response to Disasters and Outbreaks by Tracking Population Movements with Mobile Phone Network Data: A Post-Earthquake Geospatial Study in Haiti," PLoS medicine, vol. 8, no. 8, 2011. 